\title{
Estimation of genetic parameters for cheese-making traits in Spanish Churra sheep
}

\author{
R. Pelayo, ${ }^{1} \odot$ B. Gutiérrez-Gil, ${ }^{1} \odot$ A. Garzón, ${ }^{2} \odot$ C. Esteban-Blanco, ${ }^{1} \oplus$ H. Marina, ${ }^{1} \oplus$ and J. J. Arranz ${ }^{1 *}$ (๑) \\ ${ }^{1}$ Departamento de Producción Animal, Facultad de Veterinaria, Universidad de León, Campus de Vegazana s/n, León 24071, Spain \\ ${ }^{2}$ Departamento de Producción Animal, Universidad de Córdoba, Córdoba 14071, Spain
}

\begin{abstract}
The global production of sheep milk is growing, and the main industrial use of sheep milk is cheese making. The Spanish Churra sheep breed is one of the most important native dairy breeds in Spain. The present study aimed to estimate genetic parameters for a wide range of traits influencing the cheese-making ability of Churra sheep milk. Using a total of 1,049 Churra ewes, we studied the following cheese-making traits: 4 traits related to milk coagulation properties (rennet coagulation time, curd-firming time, and curd firmness at 30 and $60 \mathrm{~min}$ after addition of rennet), 2 traits related to cheese yield (individual laboratory cheese yield and individual laboratory dried curd yield), and 3 traits measuring curd firmness over time (maximum curd firmness, time to attain maximum curd firmness, and syneresis). In addition, a list of milk traits, including the native $\mathrm{pH}$ of the milk and several milk production and composition traits (milk yield; the fat, protein, and dried extract percentages; and the somatic cell count), were also analyzed for the studied animals. After discarding the noncoagulating samples (only 3.7\%), data of 1,010 ewes were analyzed with multiple-trait animal models by using the restricted maximum likelihood method to estimate (co)variance components, heritabilities, and genetic correlations. In general, the heritability estimates were low to moderate, ranging from 0.08 (for the individual laboratory dried curd yield trait) to 0.42 (for the fat percentage trait). High genetic correlations were found within pairs of related traits (i.e., 0.93 between fat and dried extract percentages, -0.93 between the log of the curd-firming time and curd firmness at $30 \mathrm{~min}, 0.70$ between individual laboratory cheese yield and individual laboratory dried curd yield, and -0.94 between time to attain maximum curd firmness and syneresis). Considering all the information provided here, we suggest that in addition
\end{abstract}

Received July 30, 2020.

Accepted October 14, 2020.

*Corresponding author: jjarrs@unileon.es to the current consideration of the protein percentage trait for improving cheese yield traits, the inclusion of the $\mathrm{pH}$ of milk as a measured trait in the Churra dairy breeding program would represent an efficient strategy for improving the cheese-making ability of milk from this breed.

Key words: sheep, milk coagulation properties, heritability, genetic correlations

\section{INTRODUCTION}

Sheep milk production in the European Union, particularly in the southern countries, has historically been based on the farming of autochthonous breeds. These local breeds are usually well adapted to the conditions of the predominantly harsh environments in their production areas, but milk yields (MY) are often low (De la Fuente et al., 2006).

Churra sheep represent one of the most primitive and rustic sheep breeds on the Iberian Peninsula. For several years, this breed has been one of the most important native dairy breeds in the northwestern region of Spain. Churra sheep are mainly raised in the Duero Valley, coinciding largely with the autonomous community of Castilla y León (De La Fuente et al., 1995). The latest census data at the end of December 2018 showed a total Churra sheep population of 147,435 (145,278 females and 2,157 males; MAPAMA, 2018), which accounted for about $6.4 \%$ of the total number of Spanish dairy sheep.

The global production of sheep milk is continually growing (FAOSTAT, 2019), and the main industrial use of this milk is for cheese making (about 94\% in Spain according to data from MAPAMA, 2019). Because sheep milk is primarily used to produce high-quality cheeses in Spain, the remuneration systems for this product are based on "cheese extract" grades (i.e., the sum of the protein content and the fat content of the milk). Sheep milk (compared with the milk of other dairy species) is characterized by high lipid and protein contents of 6.9 and $5.7 \%$, respectively (Pazzola, 2019). For this reason, sheep milk selection programs usually 
use an index that considers liters of milk and a reduced protein percentage as selection criteria.

The breeding program for the Churra breed started in 1986 with the main objective of increasing the MY, which is measured in kilograms of milk produced over a lactation period of 120 d (De La Fuente et al., 1995). Almost all the Churra milk is used for cheese production, and consequently, milk content traits are also important because they affect cheese yield. The negative genetic correlation between MY and content traits increased the need for introducing fat and protein percentages as selection criteria in some breeds (Carta et al., 2009). Thus, in 1998, the percentage of protein (PP) in the milk was included as a selection criterion for the Churra breed. For all these reasons, in the current Churra sheep breeding program for milk production, the improvement of both the milk quantity (selecting for the MY trait) and cheese yield of the milk (selecting for the PP trait) are primary selection objectives.

In addition to milk composition and cheese yield traits of dairy ruminant species, various aspects of milk coagulation properties (MCP) have been shown to influence the technological behavior of milk and therefore the efficiency of the cheese-making process. These properties can be studied by using either mechanical or optical devices. They are usually measured using a Formagraph viscometer following the method developed by McMahon and Brown (1982). Different studies have shown that the MCP of sheep milk seem to differ from those reported for cow's milk (Pazzola et al., 2014). In addition, whereas some studies in the Sarda breed indicated that coagulation was faster in sheep milk than in cow milk (Pazzola et al., 2014), a study performed by our research group on Spanish Assaf sheep described a slower coagulation process for milk from this breed (Sánchez-Mayor et al., 2019). These discrepancies highlight the need to further explore milk coagulation determinants in different sheep breeds (Pazzola et al., 2014). Technological traits associated with MCP are increasingly being considered in research, although they are still not among the traits routinely measured for official dairy control.

Notably, the cheese yield from ewe milk is almost twice that obtained from cow or goat milk (Assenat, 1985). According to Othmane et al. (2002b), milk fat and protein content seem useful but are insufficient to determine the yield and quality of the final product. Therefore, the study of traits related to cheese yield is becoming increasingly important. Similar to MCP, cheese yield traits are also not measured for official dairy control, and only the PP trait provides information on cheese yield.
Recently, new modeling techniques have been developed to better describe milk coagulation and curd firmness and syneresis, using all the information recorded during lactodynamic tests. Bittante (2011) and Bittante et al. (2013) proposed the extension of Formagraph analyses to $60 \mathrm{~min}$ and the elaboration of statistical models to examine complete data sets extrapolated from the traditional Formagraph layout. The new parameters of the curd reaffirmation and syneresis model, also called traits of curd firmness over time, have been extensively studied from a phenotypic point of view in Sarda sheep by Vacca et al. (2015).

Different studies on sheep have shown that through the estimation of genetic parameters, cheese-making traits can be improved by genetic strategies. In the literature, estimates of heritability, ranging from 0.11 to 0.30 for MCP and curd firmness over time (Bittante et al., 2017; Sánchez-Mayor et al., 2019) and from 0.08 to 0.30 for cheese yield traits (Othmane et al., 2002b; Sánchez-Mayor et al., 2019), have been reported. The estimation of genetic parameters can also be used to assess whether genetic correlations among different groups of traits (e.g., traits related to milk and MCP) may have positive or negative indirect effects when the selection practices do not consider all the traits of interest.

Taking into account the interest that the dairy sheep industry has in maximizing the efficiency of the cheese-making process and the interest that Churra sheep breeders could have in genetically improving their sheep to increase the cheese-making ability of this breed's milk, the present study aims to estimate genetic parameters for 3 groups of traits characterizing the technological behavior of the milk; namely, MCP, cheese yield, and traits related to curd firmness over time. Furthermore, this study reports the phenotypic and genetic correlations among the studied cheesemaking traits and other classical milk traits, including traits related to milk production and composition, as well as $\mathrm{pH}$ and SCC.

\section{MATERIALS AND METHODS}

\section{Animals, Sampling, and Laboratory Analyses of Milk}

The study involved 1,049 Churra ewes from 2 different flocks located in the region of Castilla y León (Spain). Considering the intensive individual milk sampling required for this work, these 2 flocks were chosen because they were large ( $>600$ dairy ewes) and well-connected flocks ( $>60 \%$ of AI animals). This selection was carefully performed to ensure the study of flocks that were genetically highly connected with 
the global Churra population and to ensure the largest number of milk samples available for analysis. The available pedigree information for the sampled ewes included 5,803 individuals. Individual milk samples were collected from each ewe once (approximately $100 \mathrm{~mL}$ ) between July and December 2019. All the laboratory analyses of these samples were performed in the Small Ruminant Dairy Laboratory (University of Córdoba, Spain) within $24 \mathrm{~h}$ after sampling. The milk samples were kept refrigerated during transportation from the farms to the laboratory. The milk samples were divided into 2 subsamples of $50 \mathrm{~mL}$ each and analyzed for 2 groups of traits.

Group 1 centered on "milk traits" including MY, PP, fat percentage (FP), dried extract percentages (DEP), SCC (number of cells per milliliter), and the $\mathrm{pH}$ of the milk. The $\mathrm{pH}$ was measured with a Crisson Basic $20 \mathrm{pH}$ meter (Crisson Instruments S.A., Barcelona, Spain), and the milk components (FP, PP, and DEP) were directly determined by mid-infrared spectroscopy using a MilkoScan FT120 (Foss Electric, Hillerød, Denmark). The SCC was measured using a Fossomatic FC (Foss Electric) and expressed as cells per milliliter.

Group 2 was focused on cheese-making traits, which were divided into 3 subgroups: MCP, cheese yield traits, and curd firmness over time. The first 2 trait groups, MCP and cheese yield traits, were measured as described in an earlier study performed by our research group on Spanish Assaf sheep (Sánchez-Mayor et al., 2019). Briefly, the MCP included were rennet coagulation time (RCT, min), defined as the time between rennet addition and the start of the milk coagulation process; curd-firming time $\left(\mathbf{k}_{\mathbf{2 0}}, \mathrm{min}\right)$, which was the time necessary for the curd to reach a $20-\mathrm{mm}$ firmness; and, the curd firmness measured in millimeters at 30 and 60 min after rennet addition $\left(\mathbf{a}_{30}\right.$ and $\mathbf{a}_{60}$, respectively). The traits related to the MCP were monitored at $32^{\circ} \mathrm{C}$ using a Formagraph viscometer (Foss Electric) and a commercial liquid rennet extract diluted to $4 \%$ in distilled water for $30 \mathrm{~min}$ (Caballero-Villalobos et al., 2018b). With regard to the cheese yield traits, individual laboratory cheese yield (ILCY, g/10 mL of milk) was determined following Othmane et al. (2002a,b) by weighing the drained curds obtained by the centrifugation of the gels resulting from the coagulation process. The individual laboratory dried curd yield (ILDCY, $\mathrm{g} / 10 \mathrm{~mL}$ ) was estimated by weighing the cooled and drained curds (after $24 \mathrm{~h}$ at $100^{\circ} \mathrm{C}$; see more details in Sánchez-Mayor et al., 2019). Finally, some traits related to curd firmness over time were analyzed for the first time in the Churra breed. During the lactodynamographic test, the instrument records the firmness of the milk samples every $15 \mathrm{~s}$, for a total of 240 observations over $60 \mathrm{~min}$, and these measurements are used to calculate curd firmness over time (Pazzola, 2019). Specifically, 3 of these new traits were analyzed in the present paper according to the 4-parameter model described by Bittante et al. (2013): maximum curd firmness $\left(\mathbf{C F}_{\text {max }}\right.$, $\mathrm{mm}$ ), time to attain $\mathrm{CF}_{\max }\left(\mathbf{t}_{\max }\right.$, min), and syneresis (Syn, mm).

\section{Basic Statistics and Genetic Parameter Estimation}

A total of 15 traits were initially considered for the estimation and analysis of genetic parameters (MY, FP, PP, DEP, SCC, pH, RCT, $\mathrm{k}_{20}, \mathrm{a}_{30}, \mathrm{a}_{60}$, ILCY, ILDCY, $\mathrm{CF}_{\max }, \mathrm{t}_{\max }$, and Syn). Noncoagulating samples were eliminated, as were records for which most of the traits were missing. After evaluating the data distribution for each trait, the SCC and $\mathrm{k}_{20}$ traits were transformed using a logarithmic transformation to normalize their distributions ( $\log \mathrm{SCC}$ and $\log \mathrm{k}_{20}$, respectively). No appropriate transformations were identified for the $\mathrm{a}_{60}$ and Syn traits, which showed a bimodal and a close to zeroinflated distribution, respectively. The basic descriptive statistics and the phenotypic distributions of the milk and cheese-making traits considered in the later analyses are given in Table 1 and Supplemental Figure S1 (https://data.mendeley.com/datasets/j98k6dc7p6/1), respectively.

Here, a general linear model analysis was performed with R software (R Core Team, 2013) to evaluate the influence of the following fixed factors: DIM (as a covariate), age at parturition, flock test day, and the number of lambs born. Because most of the effects were highly significant $(P<0.001)$ for all the studied traits, all were included in the models applied to estimate the genetic parameters.

The (co)variance components, heritabilities, and genetic correlations were obtained with multiple-trait animal models by using the restricted maximum likelihood methodology implemented in VCE v.6.0 software (Groeneveld, 2010). The multiple trait model applied to the data set considered here was as follows:

$$
Y_{i j k l m}=\mathrm{AGE}_{i}+\mathrm{FTD}_{j}+\mathrm{NLB}_{k}+\mathrm{DIM}_{l}+a_{m}+r_{i j k l m},
$$

where $Y_{i j k l m}$ is the individual trait values for each trait, $\mathrm{AGE}_{i}$ is the fixed effect of the age at parturition in 7 levels (animals under 13 mo; animals 13-18, 19-24, 25-36, 37-48, and 49-84 mo; and animals greater than $85 \mathrm{mo}), \mathrm{FTD}_{j}$ is the fixed effect of flock test-day (10 levels), $\mathrm{NLB}_{k}$ is the fixed effect of the number of lambs born (2 levels), $\mathrm{DIM}_{l}$ is the fixed effect of DIM (as a covariate), $a_{m}$ is the random additive genetic effects of the animal ( $m=1$ to 1,010$)$, and $r_{i j k l m}$ is the random re- 
sidual effect. The distributions of the sampled animals based on the considered fixed effects, AGE, FTD, and NLB, are shown in Supplemental Table S1 (https:// data.mendeley.com/datasets/j98k6dc7p6/1). The corresponding distribution based on the DIM effect (as a covariate) is represented in Supplemental Figure S2 (https://data.mendeley.com/datasets/j98k6dc7p6/1).

In addition, a principal component analysis was performed with the $\mathrm{R}$ software (R Core Team, 2013) to graphically assess the phenotypic variance in all the studied traits in the present work.

\section{RESULTS AND DISCUSSION}

Dairy sheep are traditionally reared in Mediterranean areas. In recent decades, dairy sheep systems have maintained their dual purpose, with milk and meat contributing $65-75 \%$ and $25-35 \%$ of the total income of systems, respectively. Due to the importance of highquality cheese production in dairy sheep, the study and control of the genetic and environmental factors influencing milk production and quality traits as well as the technological properties of sheep's milk are major challenges for the dairy sheep industry. The search for new analytical techniques for dairy sheep that can reduce the cost of cheese-making trait phenotyping are being studied (Ferragina et al., 2017). Interest in using Fourier-transform infrared spectroscopy technology to analyze milk and dairy products has been growing in recent decades because, with proper calibration, it is a fast and cheap technique (De Marchi et al., 2014).
However, studies carried out in sheep have been scarce in this field.

Of the 1,049 samples analyzed in the current study, only 39 did not coagulate, representing approximately $3.7 \%$ of the total analyzed samples and confirming the excellent coagulation potential of Churra sheep milk. The 39 noncoagulating samples were excluded from the study, leaving a total of 1,010 milk samples for subsequent analyses. The percentage of noncoagulating samples was similar to that reported by Bittante et al. (2014) for Alpine sheep (3.8\%). In contrast, it was lower than the $13 \%$ of noncoagulating samples observed in Spanish Assaf sheep by Sánchez-Mayor et al. (2019). One of the most influential factors for MCP is DIM, as indicated by Puledda et al. (2017) in the Sarda breed. These authors showed how the percentage of noncoagulating samples tended to increase as lactation progressed. Although comparisons are not easy because DIM was considered as a covariate in our analysis and the lactation of Churra sheep is shorter than Sarda sheep, we observed a similar trend of an increased percentage of noncoagulating samples at late lactation.

\section{Descriptive Statistics for Cheese-Making Traits}

Focusing on the cheese-making traits and comparing these results with those from studies of other breeds, we found that the average values for the traits related to the speed of the milk coagulation process, RCT and $\log k_{20}$ (17.47 and $0.40 \mathrm{~min}$, respectively), were higher

Table 1. Descriptive statistics for the milk and cheese-making traits analyzed for the coagulating samples in the present work for the Churra sheep breed

\begin{tabular}{|c|c|c|c|c|}
\hline Trait $^{1}$ & Mean & Mean error & SD & $\mathrm{CV} \%$ \\
\hline \multicolumn{5}{|c|}{ Milk yield and composition } \\
\hline MY, L/d & 1.71 & 0.02 & 0.65 & 38.01 \\
\hline $\mathrm{FP}, \%$ & 6.32 & 0.05 & 1.54 & 24.37 \\
\hline $\mathrm{PP}, \%$ & 5.42 & 0.02 & 0.65 & 11.99 \\
\hline DEP, $\%$ & 17.37 & 0.06 & 2.04 & 11.74 \\
\hline $\operatorname{logSCC}$ & 2.34 & 0.02 & 0.68 & 29.06 \\
\hline $\mathrm{pH}$, units & 6.56 & 0.00 & 0.12 & 1.83 \\
\hline \multicolumn{5}{|l|}{ Cheese-making traits } \\
\hline $\mathrm{RCT}, \min$ & 17.47 & 0.22 & 6.98 & 39.95 \\
\hline $\log k_{20}, \min$ & 0.40 & 0.01 & 0.25 & 62.50 \\
\hline $\mathrm{a}_{30}, \mathrm{~mm}$ & 36.81 & 0.42 & 13.47 & 36.59 \\
\hline $\mathrm{a}_{60}, \mathrm{~mm}$ & 39.88 & 0.41 & 13.05 & 32.72 \\
\hline ILCY, g/10 mL & 2.67 & 0.02 & 0.73 & 27.34 \\
\hline ILDCY, g/10 mL & 1.12 & 0.01 & 0.36 & 32.14 \\
\hline $\mathrm{CF}_{\max }, \mathrm{mm}$ & 43.98 & 0.29 & 9.44 & 21.46 \\
\hline $\mathrm{t}_{\max }, \min$ & 39.06 & 0.44 & 14.17 & 36.28 \\
\hline Syn, mm & 4.25 & 0.18 & 5.90 & 138.82 \\
\hline
\end{tabular}

${ }^{1} \mathrm{MY}=$ milk yield; FP, PP, and DEP $=$ fat, protein, and dried extract percentages, respectively; $\operatorname{logSCC}=$ somatic cell count expressed in $\log _{10} ; \mathrm{pH}=$ native $\mathrm{pH}$ of milk (unit); $\mathrm{RCT}=$ rennet coagulation time; $\operatorname{logk}_{20}=$ curd firming time expressed in $\log _{10} ; \mathrm{a}_{30}$ and $\mathrm{a}_{60}=$ curd firmness at 30 and 60 min after rennet addition; ILCY $=$ individual laboratory cheese yield; ILDCY $=$ individual laboratory dried curd yield; $\mathrm{CF}_{\max }=$ maximum curd firmness; $\mathrm{t}_{\max }=$ time to attain $\mathrm{CF}_{\max } ; \mathrm{Syn}=$ syneresis. 
than those reported for Sarda sheep by Pazzola (2019; 8.7 and $0.28 \mathrm{~min}$ for RCT and $\log \mathrm{k}_{20}$, respectively). In the milk of Alpine sheep breeds, Bittante et al. (2014) also found lower values (average values of $6.5 \mathrm{~min}$ for $\mathrm{RCT}$ and $0.18 \mathrm{~min}$ for $\log \mathrm{k}_{20}$ ) than those observed in the Churra breed. However, for these traits, SánchezMayor et al. (2019) reported much higher average values (29.6 and 1.35 min for RCT and $\log k_{20}$, respectively). Concerning the firmness-related traits, the $\mathrm{a}_{30}$ average value observed here for Churra sheep $(36.81 \mathrm{~mm})$ was intermediate between the very low values reported for this trait in cattle $(29.9 \mathrm{~mm})$ (Bittante et al., 2012) and Assaf sheep (28.90 mm) (Sánchez-Mayor et al., 2019) and the high value reported for Sarda sheep $(52.9 \mathrm{~mm})$ (Bittante et al., 2017). The average $\mathrm{a}_{60}$ value for Churra sheep $(39.88 \mathrm{~mm})$ was similar to that found in Assaf sheep by Sánchez-Mayor et al. (2019) but lower than the values reported for other breeds, such as Sarda (43.5 $\mathrm{mm}$ ), Manchega (52.5 mm), and Merinos (44.02 and $60.53 \mathrm{~mm}$; Bittante et al., 2017; Caballero-Villalobos et al., 2018a). Most of the samples analyzed showed the highest curd firmness value at $30 \mathrm{~min}$. This outcome suggests that the $\mathrm{a}_{60}$ trait does not provide useful information on curd firmness for Churra sheep, as can be inferred from the bimodal distribution observed for this trait (Supplemental Figure S1). Therefore, the $\mathrm{a}_{60}$ trait was discarded from the subsequent genetic parameter analyses.

In relation to the efficiency of the cheese-making process, short coagulation times (RCT and $\log _{20}$ ) and high firmness values $\left(\mathrm{a}_{30}\right)$ are desirable. The observed average values suggest that milk from Churra sheep shows intermediate coagulation properties between Assaf sheep, which is a breed of slow milk coagulation, and other breeds, such as Manchega and Sarda, that have very fast coagulation.

Regarding the cheese yield-related traits, the mean values reported here for ILCY and ILDCY were slightly higher for the Churra breed (2.67 and $1.12 \mathrm{~g} / 10 \mathrm{~mL}$, respectively) than for the Assaf breed (2.49 and $0.96 \mathrm{~g} / 10$ $\mathrm{mL}$, respectively) (Sánchez-Mayor et al., 2019). However, the average ILCY value observed in Churra sheep was lower than that reported in other Spanish breeds, such as Manchega, Merino de Grazalema, and Merino de los Pedroches (3.25, 3.15, and $3.67 \mathrm{~g} / 10 \mathrm{~mL}$, respectively) (Caballero-Villalobos et al., 2018a). Finally, few studies analyze genetic parameters for traits associated with curd firmness over time. The introduction of the concept of curd firming over time, which is independent of the traditional MCP, provides additional information about milk coagulation and curd-firming processes (Bittante, 2011). Our results showed an average $\mathrm{CF}_{\max }$ value of $43.98 \mathrm{~mm}$, and the time to reach this value $\left(t_{\max }\right)$ was $39.06 \mathrm{~min}$. These values were lower than those found in Sarda sheep by Bittante et al. (2017), for which a higher $\mathrm{CF}_{\max }$ value $(54.4 \mathrm{~mm})$ was achieved in a shorter time ( $\mathrm{t}_{\max }$ of $\left.28 \mathrm{~min}\right)$. The last of the traits related to curd firmness over time analyzed in the present work was the measurement of syneresis. As shown in Supplemental Figure S1, the distribution of this trait showed that syneresis occurred in approximately half of the studied milk samples. This finding is lower than the value reported for Sarda ewes by Vacca et al. (2015), who concluded that in contrast to bovine species, ovine species are characterized by having a variable number of ewes that produce milk that does not show any sign of syneresis, while others produce milk with high syneresis rates.

\section{Genetic Parameter Estimations}

Heritability Estimates. Regarding the genetic parameters presented in Table 2, we observed that in general, the heritability estimates were low to moderate, ranging from 0.08 (for the ILDCY trait) to 0.42 (for the FP trait). Focusing on the milk traits, we observed that most of the traits showed moderate heritability, with the MY trait (0.17) having the lowest estimate. In general, the heritabilities obtained for the milk traits are within the ranges reviewed by Carta et al. (2009). However, it is necessary to emphasize the high heritability estimated here for the FP trait in Churra sheep (0.42), which was previously estimated to be 0.06 by Othmane et al. (2002b). Nevertheless, the estimate of the FP provided here is within the range reported for different breeds in the review by Carta et al. (2009) and supports the interpretation by these authors that the low heritability estimate obtained for Churra sheep by Othmane et al. (2002b) could be due to difficulties in homogenizing the milk sample during the milk control process. The highly consistent milk sampling procedure used in 2 flocks with a similar management system may explain the estimate reported here.

The heritability estimates observed here for the cheese-making traits were low to moderate, ranging from 0.08 for the ILDCY trait to 0.26 for the $\log k_{20}$ trait. Of the 3 subgroups that constitute the cheesemaking traits, the traits related to the MCP showed the highest heritability estimates (ranging from 0.16 to 0.26 for the $\mathrm{a}_{30}$ and $\operatorname{logk}_{20}$ traits, respectively). For this subgroup, our estimates were higher than those reported by Bittante et al. (2017) for Sarda sheep but, in general, were very similar to those found by SánchezMayor et al. (2019) for Assaf sheep. Note that the heritability reported for the $\mathrm{a}_{30}$ trait in Assaf sheep (0.30) was higher than the estimated heritability reported here (0.16), which appears to be an artifact linked to the slow coagulation that characterizes Assaf milk. 


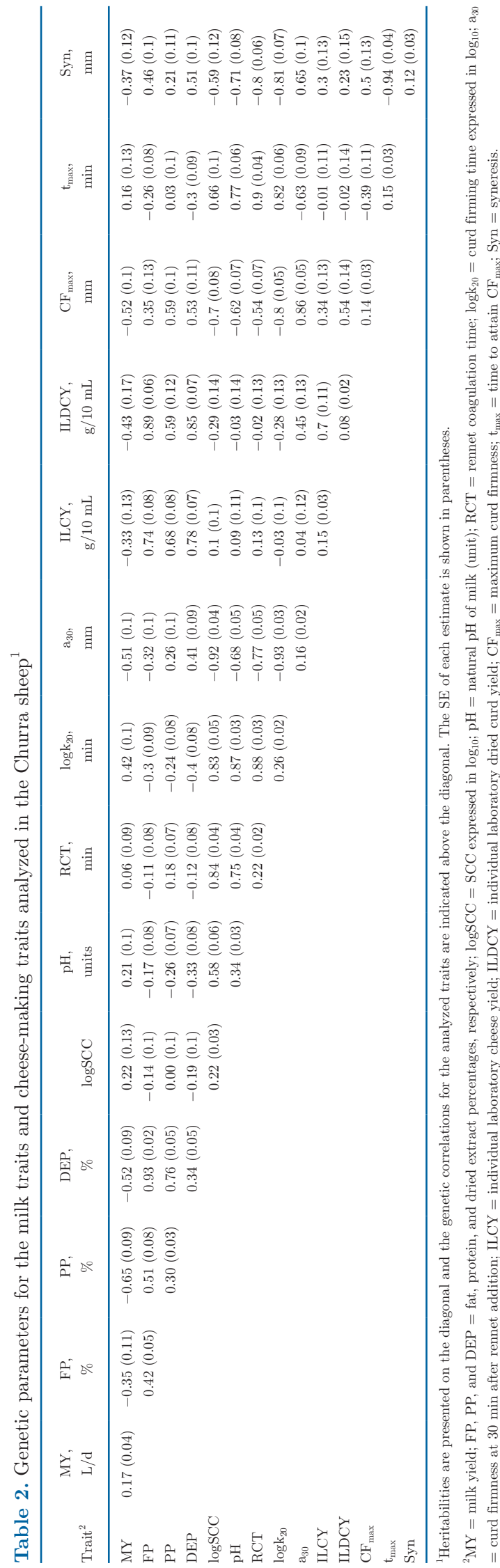

Regarding the cheese yield traits, the heritability estimate for the ILCY trait in this study (0.15) was similar to that found for Sarda sheep (0.16; Puledda et al., 2017) and lower than that found for Assaf sheep (0.30; Sánchez-Mayor et al., 2019), although it was higher than the estimate previously reported for Churra sheep (0.09; Othmane et al., 2002b). The ILDCY trait has also been studied in the Assaf breed (Sánchez-Mayor et al., 2019), again showing higher heritability estimates (0.15) than the Churra breed (0.08). Finally, the heritability values obtained for the traits related to curd firmness over time, which have been scarcely studied in sheep, ranged from 0.12 for Syn to 0.15 for $t_{\max }$ and were slightly higher than those found in Sarda sheep (0.11 and 0.12 for $t_{\max }$ and $\mathrm{CF}_{\max }$, respectively; Bittante et al., 2017). The heritability estimates described for these traits in Brown Swiss cows are higher than those reported here (Cecchinato et al., 2015).

Phenotypic and Genetic Correlations. An understanding of the relationship between the studied traits can help inform the efficient development of selection strategies aimed at the genetic improvement of the target trait. Most of the phenotypic correlations shown in this work were low to moderate, and only $2 \%$ of the phenotypic correlations estimated here were higher than 0.8 (data not shown). A principal component analysis was performed to graphically represent the relationships among the different milk and cheese-making traits. The first component explained $27.2 \%$ of the total variance, the second explained $24.6 \%$, and the third explained $16.4 \%$ (Figure 1). As shown in Figure 1a, the first and second components clearly discriminated the $\mathrm{a}_{30}$ firmness trait from the dynamic coagulation traits (RCT and $\left.\log _{20}\right)$ as well as from $\mathrm{pH}$ and $\log \mathrm{SCC}$. These 2 principal components also showed that the milk content traits (FP, PP, and DEP), together with the cheese yield traits (ILCY and ILDCY), were clearly separated from MY and Syn. Finally, the third component mainly separated the Syn trait from the $t_{\max }$ trait and from the following traits: $\log \mathrm{k}_{20}, \mathrm{RCT}, \mathrm{a}_{60}, \mathrm{CF}_{\max }, \mathrm{pH}, \log \mathrm{SCC}$, and MY. In general, the directions of the relationships between the different groups of traits observed through this principal component analysis for Churra sheep are in agreement with those reported for Assaf sheep by Sánchez-Mayor et al. (2019).

The genetic correlations estimated in this study for Churra sheep showed very low errors, which supports the accuracy of the estimates presented in Table 2. As expected, high genetic correlations were found between pairs of related traits. For example, within the milk traits, the genetic correlation estimate between the FPDEP traits was 0.93. Among the traits related to the MCP, the estimates for the RCT- $\log k_{20}$ and $\log k_{20}-a_{30}$ trait pairs were 0.88 and -0.93 , respectively, whereas 
a)

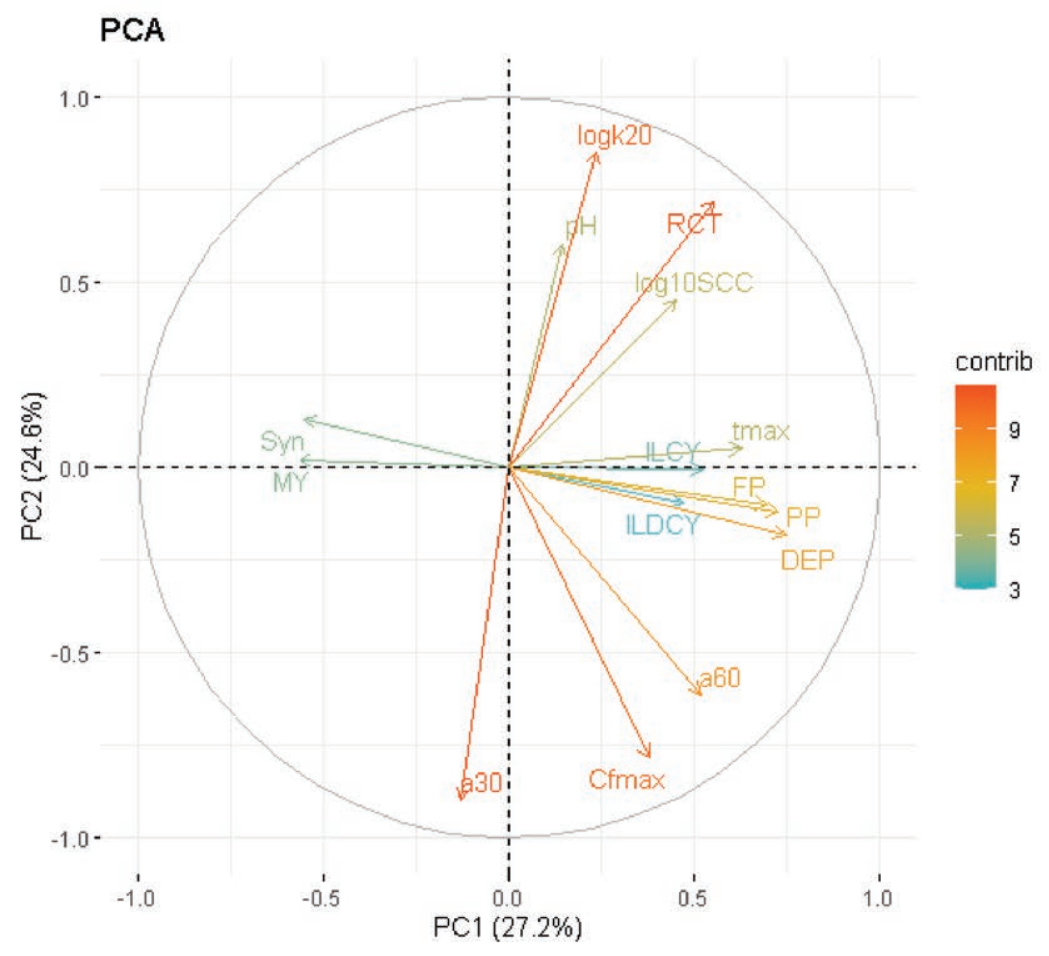

b)

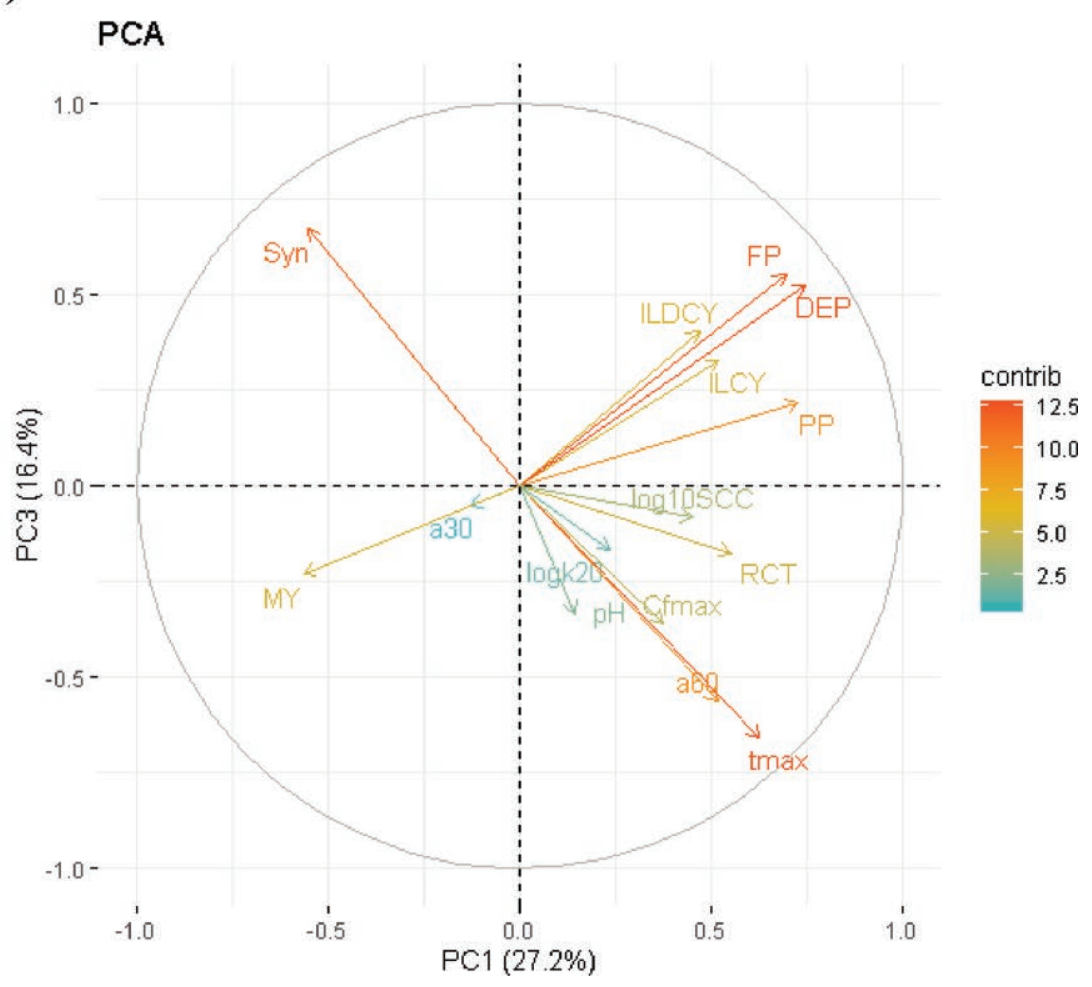

Figure 1. Graphical representation of the results from the principal component analysis (PCA) performed in the present work from the milk and the cheese-making traits: (a) component 1 versus component 2, and (b) component 1 versus component 3. MY = milk yield; FP, PP, and $\mathrm{DEP}=$ fat, protein, and dried extract percentages, respectively; logSCC $=\mathrm{SCC}$ expressed in $\log _{10} ; \mathrm{pH}=\mathrm{native} \mathrm{pH}$ of milk $($ unit); $\mathrm{RCT}=$ rennet coagulation time; $\log \mathrm{k}_{20}=$ curd firming time expressed in $\log _{10} ; \mathrm{a}_{30}$ and $\mathrm{a}_{60}=$ curd firmness at 30 and 60 min after rennet addition; ILCY $=$ individual laboratory cheese yield; ILDCY $=$ individual laboratory dried curd yield; $\mathrm{CF}_{\max }=$ maximum curd firmness; $\mathrm{t}_{\max }=$ time to attain $\mathrm{CF}_{\max } ; \mathrm{Syn}=$ syneresis; contrib $=$ contribution. 
for the ILCY-ILDCY trait pair (cheese yield traits), the estimate was 0.70. Additionally, for the newly analyzed traits related to curd firmness over time, the genetic correlation for the $t_{\max }$-Syn pair was very high, although negative $(-0.94)$. These results are in agreement with those published by other authors who also found moderate to high genetic correlations between pairs of related traits (Puledda et al., 2017; Bittante et al., 2017; Sánchez-Mayor et al., 2019). Hence, it can be suggested that when assessing the traits to be included in a selection program aiming to improve cheese-making traits, only one trait of each of these pairs should be analyzed. This approach would provide the information of interest in the corresponding property at an affordable cost.

Concerning the milk traits, we found that all the genetic correlations observed followed the expected pattern; that is, the genetic correlations found between milk composition traits were high and positive (0.93 for the FP-DEP pair and 0.76 for the PP-DEP pair). Likewise, the $\mathrm{pH}$ was negatively correlated with the milk content traits $(-0.17,-0.26$, and -0.33 for the FP, $\mathrm{PP}$, and DEP, respectively) but positively correlated with the $\operatorname{logSCC}(0.58)$. Finally, MY was negatively correlated with the FP $(-0.35)$, PP $(-0.65)$, and DEP $(-0.52)$ and positively correlated with the logSCC $(0.22)$ and $\mathrm{pH}(0.21)$. In general, the genetic correlations identified between the milk traits are consistent with those reported in previous studies (Cassandro et al., 2008; Carta et al., 2009). Interestingly, the positive genetic correlation estimated here for the MY-logSCC pair reflects a moderate genetic antagonism between these 2 traits because an improvement leading to higher MY would be associated with an increase in SCC, which has a negative impact on the commercial quality of milk. However, throughout the literature, the estimated genetic correlations between these 2 traits show a wide range of variation across different populations. In this regard, a study in the Lacaune breed showed that the sign and magnitude of the genetic correlation between this pair of traits changes across the lactation period (Barillet et al., 2001).

Analyzing the genetic correlations among the cheesemaking traits in detail, we observed some interesting estimates for the Churra sheep breed. As mentioned above, we found high genetic correlations between the traits related to the MCP traits (positive correlations between RCT-logk $\mathrm{k}_{20}$ and negative correlations between these 2 traits and $\mathrm{a}_{30}$ ), which is consistent with the estimates obtained by other authors (Puledda et al., 2017; Sánchez-Mayor et al., 2019). The strong negative correlations between the coagulation time-related traits (RCT and $\log k_{20}$ ) and the curd firmness traits suggest that when milk coagulates faster, more time is available for the curd-firming process. However, no clear relationship was found between the traits related to the MCP and cheese yield, and only the $\mathrm{a}_{30}$-ILDCY pair showed a moderate genetic correlation (0.45). In the Assaf breed, Sánchez-Mayor et al. (2019) found a slightly lower estimate between this pair of traits (0.34), but due to its high standard error, it was an inaccurate estimate. However, it is important to consider that other researchers have found strong correlations between these groups of traits (Puledda et al., 2017). These discrepancies highlight the value of assessing the relationship between traits related to MCP and cheese yield in different breeds. In the present study, some traits related to curd firmness over time were analyzed for the first time in the Churra sheep breed. Interestingly, all the genetic correlations found between the traits related to the MCP and curd firmness over time were moderate to high (ranging from -0.54 to 0.90 for the RCT-CF $\mathrm{max}_{\max }$ and $\mathrm{RCT}-\mathrm{t}_{\max }$ trait pairs, respectively), indicating a strong common genetic background between both groups of traits in this breed. This means that in Churra sheep, a slower milk coagulation process is associated with a lower maximum curd firmness and a longer time to reach that firmness value.

It should be noted that the $\log k_{20}$ trait showed genetic correlations higher than 0.8 with the 3 traits related to curd firmness traits over time. Therefore, $\log k_{20}$ may be considered a good candidate trait for use as a selection index for the improvement of traits related to curd firmness over time in the Churra breed (e.g., to minimize the syneresis phenomenon). Our estimates are generally higher than those found in Sarda ewes by Bittante et al. (2017), who also obtained a positive genetic correlation between $\mathrm{a}_{30}$ and $\mathrm{t}_{\max }(0.35)$, while a negative estimate was found in this work for the same pair of traits $(-0.63)$. Additionally, in general, no strong genetic correlations were found between the yield traits and the traits related to curd firmness over time. We found only moderately positive estimates between the ILCY - $\mathrm{CF}_{\max }(0.34)$ and the ILDCY-CF $\max (0.54)$ pairs. We acknowledge the difficulties in comparing genetic correlations for these traits among different studies because, in some cases, different methodologies have been used to measure the trait. In contrast, in other cases, the comparison is invalid due to some estimates being associated with high standard errors (which depends on the genetic structure of the studied population). In the present study, the estimates appear to be reliable and offer a preliminary idea of the level and direction of the genetic relationship underlying cheese-making traits.

Genetic Correlations Between Milk and Cheese-Making Traits. Finally, given that the main selection objectives in the Churra breeding program are MY and protein percentage, it is interesting to 
examine the genetic correlations obtained between the milk traits and cheese-making traits. In general, the lower standard errors of the genetic correlations reported here compared with those reported in other studies (Puledda et al., 2017; Sánchez-Mayor et al., 2019) support the use of our estimates to assess the genuine genetic relationship between milk traits and cheese-making traits in Churra sheep. The FP, PP, and DEP traits showed negative and low to moderate genetic correlations with $\log k_{20}$. Nevertheless, in general, high genetic correlations between the traits related to the milk components and MCP were not observed in Churra sheep. However, in Sarda sheep, Bittante et al. (2017) found a strong positive correlation for the PPRCT pair (0.76). As expected, the genetic correlations obtained between the milk component traits (FP, PP, and DEP) and cheese yield traits (ILCY and ILDCY) were positive and varied from moderate to high (ranging from 0.59 to 0.89 for the PP-ILDCY and FP-ILDCY trait pairs, respectively).

These results are consistent with the genetic correlations found for these 2 groups of traits in Assaf sheep (Sánchez-Mayor et al., 2019), the estimates of which were also high and positive (ranging from 0.60 to 0.89 for the FP-ILDCY and PP-ILDCY trait pairs, respectively). These results are also in agreement with those reported in Sarda (0.45 and 0.75) and Churra (0.60 and 0.76) sheep (Puledda et al., 2017; Othmane et al., 2002b). The positive association found between these groups of traits provides favorable information on a practical level because by selecting in favor of high milk fat or protein, we may indirectly improve cheese yield. This is, in general, the current strategy of many sheep breeding programs for milk production, wherein cheese-making traits are not measured routinely and the PP trait is used as a proxy. Finally, the genetic correlations found between the milk composition traits and traits related to curd firmness over time were low to moderate, ranging from $0.03\left(\mathrm{PP}_{\mathrm{m}} \mathrm{t}_{\max }\right)$ to 0.56 (PP$\left.\mathrm{CF}_{\max }\right)$. In Sarda ewes, milk fat content was found to be positively genetically associated with all measures of curd firmness over time (Bittante et al., 2017); however, in our study, the FP- $\mathrm{t}_{\max }$ correlation was negative $(-0.26)$. Therefore, in the Churra breed, a clear association between the milk composition traits and traits related to curd firmness over time has not been found.

Both $\mathrm{pH}$ and $\log \mathrm{SCC}$ showed a similar pattern of genetic correlations with the cheese-making traits. The genetic correlations between the $\mathrm{pH}$ and traits related to the MCP were moderate to high, ranging from -0.68 $\left(\mathrm{pH}-\mathrm{a}_{30}\right)$ to $0.87\left(\mathrm{pH}-\log \mathrm{k}_{20}\right)$. No strong association was found between $\mathrm{pH}$ and the cheese yield traits, and moderate to high genetic correlations were found between $\mathrm{pH}$ and the traits related to curd firmness over time.
The genetic correlations found between the $\operatorname{logSCC}$ and the other cheese-making traits are consistent with those described above for $\mathrm{pH}$. Furthermore, we highlight that the genetic correlations between the $\log \mathrm{SCC}$ and the cheese yield traits were even higher than for $\mathrm{pH}$, ranging from $0.83\left(\operatorname{logSCC}-\log k_{20}\right)$ to $-0.92\left(\operatorname{logSCC}-\mathrm{a}_{30}\right)$. These results indicate that variations in both $\mathrm{pH}$ and SCC would significantly affect the traits related to the MCP and curd firmness over time, although the effect is weaker for the latter group of traits. However, variations in the $\mathrm{pH}$ and $\operatorname{logSCC}$ would not have a remarkable impact on cheese yield traits. Among Sarda sheep, Puledda et al. (2017) showed similar estimates to those found in this study between $\mathrm{pH}$ and the traits related to the MCP. However, the genetic correlations estimated between the SCC and the rest of the cheese-making traits were inaccurate, showing large standard errors.

As a final point, considering the importance that the MY trait has in dairy sheep production, we find that understanding the relationship between this trait and cheese-making traits is highly relevant for the sheep industry. The highest genetic correlations between MY and the traits considered within each subgroup studied here were for the following pairs of traits: $M Y-a_{30}$ $(-0.51)$, MY-ILDCY $(-0.43)$, and MY-CF ${ }_{\max }(-0.52)$. These estimates show that as the MY increases, both groups of traits (i.e., the cheese yield-related traits and the traits related to curd firmness) are expected to decrease. Our results are in line with those published by other researchers (Bittante et al., 2017; Sánchez-Mayor et al., 2019) and suggest that selection for only the MY trait would have a globally negative impact on cheesemaking traits.

The estimates of the genetic parameters reported here for milk and cheese-making traits in the Churra sheep breed support the use of the PP trait as a selection criterion to improve cheese yield, as has been done in the Churra breeding program since 1998. Additionally, the heritability estimates reported here for the 3 groups of cheese-making traits studied (MCP, cheese yield traits, and traits related to curd firmness over time) indicate that these traits can be improved through genetic selection. However, considering the difficulties of using these traits in commercial populations routinely, the improvement of traits related to MCP and curd firmness over time might be possible by indirect selection if the milk $\mathrm{pH}$ was included as a measured trait in the official milk recording system. This trait shows moderate heritability and high genetic correlations with traits related to MCP and curd firmness over time in Churra sheep. Hence, measuring the $\mathrm{pH}$ and reporting it in official milk records would offer a new tool that could lead to improvements in not only the cheese yield traits but also the milk technological properties of this breed. 


\section{CONCLUSIONS}

This study provided estimates of genetic parameters for milk traits and cheese-making traits for the Churra sheep breed. Traits related to MCP and curd firmness over time had not previously been analyzed for this breed. The heritability estimates reported here for the cheese-making traits were, in general, low to moderate, suggesting that improvement in these traits may be achieved by genetic selection. The genetic correlations found in the present study showed good accuracy, supporting their ability to increase our understanding of the genuine nature of the relationships among these traits at the genetic level. Considering all the information provided here, we suggest that in addition to the current consideration of the PP trait for improving cheese yield traits, the inclusion of the $\mathrm{pH}$ of milk as a measured trait in the Churra dairy breeding program would represent an efficient strategy for improving the cheese-making ability of milk from this breed.

\section{ACKNOWLEDGMENTS}

This research work was developed under the framework of the project LE249P18 financed by the Consejería de Educación of Junta de Castilla y León (Spain) and cofounded by the European Social Fund. We want to acknowledge the support of the Castilla y León Agricultural Technology Institute (ITACYL), the Consortium for the promotion of sheep (lechedeoveja.com), and the Churra breeders association (ANCHE). R. Pelayo is funded by a postdoctoral contract co-funded by the Junta de Castilla and León Government and the European Social Fund (LE249P18). The authors have not stated any conflicts of interest.

\section{REFERENCES}

Assenat, L. 1985. Le lait de brebis. Composition et propriétés. Pages 281-294 in Laits et Produits Laitiers. Vol. 1. F. M. Luquet, ed. Tec \& Doc Lavoisier, Cachan, France.

Barillet, F., R. Rupp, S. Mignon-Grasteau, J. M. Astruc, and M. Jacquin. 2001. Genetic analysis for mastitis resistance and milk somatic cell score in French Lacaune dairy sheep. Genet. Sel. Evol. 33:397-415. https://doi.org/10.1186/1297-9686-33-4-397.

Bittante, G. 2011. Modeling rennet coagulation time and curd firmness of milk. J. Dairy Sci. 94:5821-5832. https://doi.org/10.3168/ jds.2011-4514.

Bittante, G., C. Cipolat-Gotet, M. Pazzola, M. L. Dettori, G. M. Vacca, and A. Cecchinato. 2017. Genetic analysis of coagulation properties, curd firming modeling, milk yield, composition, and acidity in Sarda dairy sheep. J. Dairy Sci. 100:385-394. https://doi.org/ 10.3168/jds.2016-11212.

Bittante, G., B. Contiero, and A. Cecchinato. 2013. Prolonged observation and modelling of milk coagulation, curd firming, and syneresis. Int. Dairy J. 29:115-123. https://doi.org/10.1016/j.idairyj 2012.10.007.

Bittante, G., E. Pellattiero, F. Malchiodi, C. Cipolat-Gotet, M. Pazzola, G. M. Vacca, S. Schiavon, and A. Cecchinato. 2014. Quality traits and modeling of coagulation, curd firming, and syneresis of sheep milk of Alpine breeds fed diets supplemented with rumenprotected conjugated fatty acid. J. Dairy Sci. 97:4018-4028. https: //doi.org/10.3168/jds.2013-7345.

Bittante, G., M. Penasa, and A. Cecchinato. 2012. Invited review: Genetics and modeling of milk coagulation properties. J. Dairy Sci. 95:6843-6870. https://doi.org/10.3168/jds.2012-5507.

Caballero-Villalobos, J., A. Figueroa, K. Xibrraku, E. Angón, J. M. Perea, and A. Garzón. 2018a. Multivariate analysis of the milk coagulation process in ovine breeds from Spain. J. Dairy Sci. 101:10733-10742. https://doi.org/10.3168/jds.2018-14752.

Caballero-Villalobos, J., J. M. Perea, E. Angón, R. Arias, and A. Garzón. 2018b. Coagulation efficiency and its determinant factors: A case study for Manchega ewe milk in the region of Castilla-La Mancha, Spain. J. Dairy Sci. 101:3878-3886. https://doi.org/10 $.3168 /$ jds.2017-13816.

Carta, A., S. Casu, and S. Salaris. 2009. Current state of genetic improvement in dairy sheep. J. Dairy Sci. 92:5814-5833. https://doi .org/10.3168/jds.2009-2479.

Cassandro, M., A. Comin, M. Ojala, R. Dal Zotto, M. De Marchi, L. Gallo, P. Carnier, G. Bittante, R. D. Zotto, M. De Marchi, L. Gallo, P. Carnier, and G. Bittante. 2008. Genetic parameters of milk coagulation properties and their relationships with milk yield and quality traits in Italian Holstein cows. J. Dairy Sci. 91:371-376. https://doi.org/10.3168/jds.2007-0308.

Cecchinato, A., S. Chessa, C. Ribeca, C. Cipolat-Gotet, T. Bobbo, J. Casellas, and G. Bittante. 2015. Genetic variation and effects of candidate-gene polymorphisms on coagulation properties, curd firmness modeling and acidity in milk from Brown Swiss cows. Animal 9:1104-1112. https://doi.org/10.1017/S1751731115000440.

De la Fuente, L., D. Gabiña, N. Carolino, and E. Ugarte. 2006. The Awassi and Assaf breeds in Spain and Portugal. Agriculture 2:1720.

De La Fuente, L. F., J. A. Baro, and F. San Primitivo. 1995. Breeding programme for the Spanish Churra sheep breed. Pages 165-172 in Strategies for Sheep and Goat Breeding. D. Gabina, ed. CIHEAM, Zaragoza, Spain.

De Marchi, M., V. Toffanin, M. Cassandro, and M. Penasa. 2014. Invited review: Mid-infrared spectroscopy as phenotyping tool for milk traits. J. Dairy Sci. 97:1171-1186. https://doi.org/10.3168/ jds.2013-6799.

FAOSTAT. 2019. Productos por Regiones. Accessed February 19, 2020. http://www.fao.org/faostat/es/\#rankings/commodities_by _regions_imports.

Ferragina, A., C. Cipolat-Gotet, A. Cecchinato, M. Pazzola, M. L. Dettori, G. M. Vacca, and G. Bittante. 2017. Prediction and repeatability of milk coagulation properties and curd-firming modeling parameters of ovine milk using Fourier-transform infrared spectroscopy and Bayesian models. J. Dairy Sci. 100:3526-3538. https://doi.org/10.3168/jds.2016-12226.

Groeneveld, E. 2010. VCE User's Guide and Reference Manual. Version 6.0. https://www.openagrar.de/servlets/MCRFileNodeServlet/ openagrar_derivate_00022208/.

MAPAMA. 2018. Programa de cría de la raza Churra. https://servicio .mapama.gob.es/arca/flujos.html?_flowId=datosCensalesRaza -flow\&tipoOperacion $=$ CONSULTA\&isMapa $=1 \& i d=50340$.

MAPAMA. 2019. Anuario de estadística 2018. https://www.mapa .gob.es/es/ganaderia/temas/produccion-y-mercados-ganaderos/ indicadoreseconomicosovinoycaprinodeleche2020_tcm30-553590 .pdf.

McMahon, D. J., and R. J. Brown. 1982. Evaluation of formagraph for comparing rennet solutions. J. Dairy Sci. 65:1639-1642.

Othmane, M. H., J. A. Carriedo, F. San Primitivo, and L. De la Fuente. 2002a. Genetic parameters for lactation traits of milking ewes: Protein content and composition, fat, somatic cells and individual laboratory cheese yield. Genet. Sel. Evol. 34:581-596. https: //doi.org/10.1186/1297-9686-34-5-581.

Othmane, M. H., L. F. De La Fuente, J. A. Carriedo, and F. San Primitivo. 2002b. Heritability and genetic correlations of test day milk yield and composition, individual laboratory cheese yield, 
and somatic cell count for dairy ewes. J. Dairy Sci. 85:2692-2698. https://doi.org/10.3168/jds.S0022-0302(02)74355-5.

Pazzola, M. 2019. Coagulation traits of sheep and goat milk. Animals (Basel) 9:540. https://doi.org/10.3390/ani9080540.

Pazzola, M., M. L. Dettori, C. Cipolat-Gotet, A. Cecchinato, G. Bittante, and G. M. Vacca. 2014. Phenotypic factors affecting coagulation properties of milk from Sarda ewes. J. Dairy Sci. 97:72477257. https://doi.org/10.3168/jds.2014-8138.

Puledda, A., G. Gaspa, M. G. Manca, J. Serdino, P. P. Urgeghe, C. Dimauro, R. Negrini, and N. P. P. Macciotta. 2017. Estimates of heritability and genetic correlations for milk coagulation properties and individual laboratory cheese yield in Sarda ewes. Animal 11:920-928. https://doi.org/10.1017/S1751731116002147.

R Core Team. 2013. R: A language and environment for statistical computing. R Foundation for Statistical Computing, Vienna.

Sánchez-Mayor, M., R. Pong-Wong, B. Gutiérrez-Gil, A. Garzón, L. F. de la Fuente, and J. J. Arranz. 2019. Phenotypic and genetic parameter estimates of cheese-making traits and their relationships with milk production, composition and functional traits in Span- ish Assaf sheep. Livest. Sci. 228:76-83. https://doi.org/10.1016/j .livsci.2019.08.004.

Vacca, G. M., M. Pazzola, M. L. Dettori, E. Pira, F. Malchiodi, C. Cipolat-Gotet, A. Cecchinato, and G. Bittante. 2015. Modeling of coagulation, curd firming, and syneresis of milk from Sarda ewes. J. Dairy Sci. 98:2245-2259. https://doi.org/10.3168/jds.2014 -8902 .

\section{ORCIDS}

R. Pelayo 나 https://orcid.org/0000-0002-9827-1292

B. Gutiérrez-Gil ๑ https://orcid.org/0000-0001-7990-5723

A. Garzón @ https://orcid.org/0000-0002-0543-5164

C. Esteban-Blanco ( https://orcid.org/0000-0002-2425-000X

H. Marina @ https://orcid.org/0000-0001-9226-2902

J. J. Arranz (1) https://orcid.org/0000-0001-9058-131X 